\title{
Choice of Treatment Regimen as Add-On to Insulin in Japanese Patients with Type 2 Diabetes Mellitus: Physicians' Perspective in a Real-World Setting, Insight from a Web Survey
}

Kota Imai · Hiroki Murayama · Takahisa Hirose

Received: June 22, 2018 / Published online: July 30, 2018

(C) The Author(s) 2018

\section{ABSTRACT}

Introduction: The Japanese guidelines emphasize treatment individualization and intensification with oral anti-diabetes drugs and glucagon-like peptide-1 receptor agonists (OADGs) as add-on therapy to insulin in the management of type 2 diabetes mellitus (T2DM). However, a step-wise treatment algorithm is not clearly defined in the Japanese guidelines. This study explores the treatment factors and patient characteristics for selecting the OADGs as add-on therapy to insulin from physicians' perspectives in a real-world setting in Japan.

Methods: This web-based survey comprised a questionnaire designed for physicians

Enhanced Digital Features To view enhanced digital features for this article go to https://doi.org/10.6084/ m9.figshare.6850010.

Electronic supplementary material The online version of this article (https://doi.org/10.1007/s13300018-0476-3) contains supplementary material, which is available to authorized users.

K. Imai · H. Murayama ( $₫)$

Medical Division, Novartis Pharma K.K., Tokyo, Japan

e-mail: hiroki.murayama@novartis.com

\section{T. Hirose}

Division of Diabetes, Metabolism and

Endocrinology, Department of Medicine, School of

Medicine, Toho University, Tokyo, Japan (diabetologists with board certification and general physicians without board certification) across Japan. The primary endpoint was the proportion of treatment factors and patient characteristics influencing the selection of OADGs as add-on therapy to insulin by the physicians.

Results: In total, 549 physicians participated. The mean number of patients treated with insulin by diabetologists $(102.2 \pm 91.2)$ in the past 6 months was higher than the number by general physicians $(35.1 \pm 44.3)$. The dipeptidyl peptidase-4 (DPP-4) inhibitors were the most frequently prescribed OADGs as add-on therapy to insulin types among the physicians (75.4-88.2\%), followed by metformin (65.2-76.3\%). The treatment factors influencing the choice of a DPP-4 inhibitor were glycated hemoglobin (HbA1c) and postprandial glucose (PPG) lowering effect, frequency of administration, effect on glucagon, and ease of use in patients with renal or liver impairment. For metformin, cost-effectiveness was the key deciding factor. The patient characteristics for the choice of DPP-4 inhibitors among diabetologists were predominantly PPG, concern about hypoglycemia, diabetes complications, and adherence to diet and exercise. For metformin, it was age, body mass index (BMI), insulin resistance, renal and liver function, and economic status of the patients.

Conclusion: DPP-4 inhibitors, followed by metformin, were the most frequently prescribed OADGs in combination with insulin in a real- 
world setting in Japan. The diabetologists considered more drug characteristics for DPP-4 inhibitor or metformin-insulin combinations. The treatment factors and patient characteristics for the choice of DPP-4 inhibitors and metformin were comparable across different insulin types.

Funding: Novartis Pharma K.K.

Keywords: Diabetologists; Dipeptidyl peptidase4 inhibitor; General physicians; Insulin; Japanese patients; Metformin; Questionnaire; Type 2 diabetes mellitus; Web-based survey

\section{INTRODUCTION}

The increasing prevalence of type 2 diabetes mellitus (T2DM) has recently placed Japan among the top five countries worldwide with approximately 7.2 million affected individuals, along with an estimated healthcare expenditure of 28 billion international dollars as described in the IDF Diabetes Atlas, 8th Edition [1] and reported to reach 10.0 million by the Ministry of Health, Labor, and Welfare. Impaired insulin secretion and increased insulin resistance are critical pathophysiologic characteristics among Japanese patients with T2DM compared with Caucasians [2-4]. The progressive nature of T2DM associated with the loss of $\beta$-cell function results in deterioration of glycemic control, which entails treatment intensification with a combination of oral anti-diabetes drugs and glucagon-like peptide-1 receptor agonists (OADGs), and eventually insulin treatment [5]. The use of insulin has become quite prevalent in the Japanese population, with $\sim 30 \%$ of patients receiving insulin either as a monotherapy or in combination with other OADGs [5-8]. Despite the availability of several OADGs and the increased use of insulin, most patients still fail to achieve glycemic control goals, which might possibly be due to increased risk of hypoglycemia, weight gain, and insufficient social support for the use of insulin, especially for patients with dementia or fear of injectables $[8,9]$. Hence, improvement in glycemic control without increasing the risk of hypoglycemia and weight gain is required when using OADGs in combination with insulin. The Japanese Diabetes Society (JDS) and the American Diabetes Association/European Association for the Study of Diabetes (ADA/EASD) guidelines recommend treatment individualization and intensification with OADGs in combination with insulin for the treatment of T2DM $[2,10]$. However, a step-wise algorithm for treatment intensification is not clearly defined in the JDS guideline. Under this circumstance, for the physicians (diabetologists with board certification and general physicians without board certification) to make the right decision about the choice and sequence of treatment regimen is challenging, in particular for general physicians, considering diverse factors such as age, co-existing illnesses, and body weight. Moreover, comorbidities resulting in polypharmacy, altered lifestyle, minimal patient-physician interaction, and complexity of the disease also pose additional barriers [11]. Hence, it is important to understand the physicians' perspectives when selecting the OADGs as add-on therapy to insulin in patients with T2DM.

Despite the increase in the number of OADGs available and recommendations on treatment individualization, there are limited data on the treatment factors or patient characteristics that influence a physician's decision when prescribing medications in patients with T2DM in real-world clinical practice. The present non-interventional online survey was designed to understand these factors affecting the choice of OADGs as add-on therapy to insulin and the rationale behind it from the physicians' perspective in Japan.

\section{METHODS}

\section{Study Design}

This non-interventional study includes an online web-based quantitative survey with a questionnaire for physicians consisting of simple, focused, multiple choice questions, with no possibility to post free text comments. The questions included in the survey covered the physician profile, number of patients treated under each insulin type, choice of OADGs used 
as combination therapy with each insulin type, and reasons for treatment choice (including drug characteristics and patients' profile). No therapy protocol, diagnostic/therapy procedure, or visit schedule was followed in the survey. The physicians were invited through the M3 website and screened by a set of questions such as number of patients with T2DM, proportion of professional time spent in patient care, and so on. The survey length was capped at 25 min to maximize respondent participation and minimize dropout rates.

\section{Physicians Recruited for the Survey}

We projected that approximately $40 \%$ of the physicians $(n=192)$ would select the most frequent drug of choice. Among them, it was assumed that physicians would select each factor ranging from $20 \%$ to $50 \%$. A half-width of $95 \%$ confidence interval (CI 4.7-5.8\%) was set to provide a range of $10 \%$ for the estimate. Therefore, approximately 480 physicians (diabetologists with board certification and general physicians without board certification) from eight different regions across Japan (Hokkaido, Tohoku, Kanto, Chubu, Kinki, Chugoku, Shikoku, and Kyushu) were planned to be included in the study. Selection of the physicians was random across Japan, and no regional bias was involved. The diabetologists were physicians who were certified by the Japan Diabetes Society (JDS) board and defined as group 1 afterwards. The general physicians mostly included primary care physicians, general practitioners, internists, and cardiologists and were defined as group 2 afterwards. The participating physicians were required to have spent more than $50 \%$ of their professional time in direct patient care and should have personally treated at least 150 patients with T2DM and prescribed insulin in the past 6 months.

\section{Study Assessments}

The primary endpoint was to identify the decision-making factors chosen for prescribing OADGs to be used in combination with insulin types (basal, pre-mix, rapid/ultra-rapid, and intensive). Secondary endpoints included the proportion of each OADG selected prior to insulin treatment.

\section{Data Management and Statistical Analysis}

The survey data were collected by M3 Global Research in Japan. The web-based questionnaire was used as a data source for the study. A statistical tool and programming language such as quantum was used for data management and protection. Categorical variables were presented as raw numbers and proportions and continuous variables as mean, standard deviation, 25 th percentile, median, 75 th percentile, and minimum and maximum values based on the distribution. Regression analyses using the Statistical Package for Social Sciences (SPSS) (IBM ${ }^{\circledR}$ SPSS ${ }^{\circledR}$ Statistics, Version 24) were used to understand the reasons for the choice of different OADGs by physicians. Multinomial logistic regression was used to assess the odds ratio (OR), taking the most frequently selected OADG as an add-on to insulin therapy and comparing it with the second most frequently prescribed OADG.

\section{Compliance with Ethics Guidelines}

The study was conducted in accordance with the Ethical Guidelines for Medical and Health Research Involving Human Subjects (the Ministry of Education, Culture, Sports, Science and Technology, and the Ministry of Health, Labor and Welfare, Japan) and with the 1964 Helsinki declaration and its later amendments or comparable ethical standards. The study protocol was reviewed and approved by a central ethics committee in Osaka, Japan.

\section{RESULTS}

\section{Background Characteristics of Physicians Participating in the Survey}

A total of 260 diabetologists with board certification (group 1) and 289 general physicians (group 2) participated in the online survey. Physicians' background details and geographical distributions are presented in Table 1 . The 
Table 1 Responders' backgrounds-physicians treating patients on insulin combinations

\begin{tabular}{|c|c|c|}
\hline & $\begin{array}{l}\text { Group 1 } \\
(n=260)\end{array}$ & $\begin{array}{l}\text { Group } 2 \\
(n=289)\end{array}$ \\
\hline Age, years & $48.0 \pm 9.5$ & $51.4 \pm 9.3$ \\
\hline $\begin{array}{l}\text { Time spent in } \\
\text { patient care, } \%\end{array}$ & $89.2 \pm 11.2$ & $91.0 \pm 9.7$ \\
\hline \multicolumn{3}{|c|}{ Practice setting, $n(\%)$} \\
\hline Hospital based & $204(78.5)$ & $173(59.9)$ \\
\hline Office based & $56(21.5)$ & $116(40.1)$ \\
\hline \multicolumn{3}{|c|}{ Medical specialty, $n(\%)$} \\
\hline $\mathrm{PCP} / \mathrm{GP}$ & $6(2.3)$ & $58(20.1)$ \\
\hline Internist & $28(10.8)$ & $139(48.1)$ \\
\hline Diabetologist & $203(78.1)$ & $21(7.3)$ \\
\hline Endocrinologist & $17(6.5)$ & $9(3.1)$ \\
\hline Cardiologist & $6(2.3)$ & $62(21.5)$ \\
\hline $\begin{array}{l}\text { Time in clinical } \\
\text { practice, years }\end{array}$ & $16.8 \pm 8.8$ & $22.2 \pm 9.3$ \\
\hline \multicolumn{3}{|l|}{ Region, $n(\%)$} \\
\hline Hokkaido & $18(6.9)$ & $19(6.6)$ \\
\hline Tohoku & $11(4.2)$ & $19(6.6)$ \\
\hline Kanto & $81(31.2)$ & $97(33.6)$ \\
\hline Chubu & $49(18.8)$ & $43(14.9)$ \\
\hline Kinki & $37(14.2)$ & $52(18)$ \\
\hline Chugoku & $14(5.4)$ & $12(4.2)$ \\
\hline Shikoku & $19(7.3)$ & $12(4.2)$ \\
\hline Kyushu & $31(11.9)$ & $35(12.1)$ \\
\hline $\begin{array}{l}\text { Number of } \\
\text { patients treated } \\
\text { with insulin in } \\
\text { the last } \\
6 \text { months }\end{array}$ & $102.2 \pm 91.2$ & $35.1 \pm 44.3$ \\
\hline
\end{tabular}

All values are mean $\pm \mathrm{SD}$ or $n(\%)$

$G P$ general practitioner, $P C P$ primary care physician, $S D$ standard deviation mean number of patients with T2DM treated with insulin in the past 6 months was higher for group 1 (102.2 \pm 91.2$)$ compared with group 2 $(35.1 \pm 44.3)$. Group 1 had more hospital-based practice settings compared with group 2. Group 2 subjects were mostly internists $(48.1 \%)$, cardiologists $(21.5 \%)$, or primary care physicians/general physicians (20.1\%) (Table 1).

\section{Choice of OADGs in Combination with Insulin}

DPP-4 inhibitors were the most frequently prescribed OADG by both group 1 and group 2 as add-on to insulin therapy (average of all insulin types; $80.4 \%)$, followed by metformin $(70.2 \%)$ and sodium-glucose co-transporter-2 (SGLT-2) inhibitors (41.5\%). Approximately $20-30 \%$ of patients were prescribed glinides or alpha-glucosidase inhibitors in combination with insulin as potentially prescribed OADGs. There was no difference in selecting the most frequently prescribed OADGs between group 1 and group 2 . Details of OADGs prescribed in combination with each type of insulin (all applicable) are described in Table $2 \mathrm{a}$ and the most frequently prescribed OADGs are presented in Table $2 \mathrm{~b}$. As DPP-4 inhibitors and metformin were the most frequently prescribed medications, henceforth in the article we focus our discussion predominantly on these two oral anti-diabetes drugs (OADs).

\section{Expectations on Reducing Insulin Dosage or Injection Frequency with OADs}

About 93\% of group 1 expected to reduce the insulin dosage or injection frequency with the addition of DPP-4 inhibitors, whereas about 94\% among group 2 expected to reduce as well. However, the expectation of reduction in dosing or injection frequency with a metformin and basal insulin combination was higher among group 1 than group 2 (91.1\% versus $84.3 \%$, respectively) (Supplementary Table 1). 
Table 2 Physicians choice of OADGs in combination with each type of insulin

\begin{tabular}{|c|c|c|c|c|}
\hline Drugs, $n(\%)$ & $\begin{array}{l}\text { Basal insulin } \\
\text { All physicians } \\
(n=549)\end{array}$ & $\begin{array}{l}\text { Pre-mixed insulin } \\
\text { All physicians }{ }^{\mathrm{a}} \\
(n=549)\end{array}$ & $\begin{array}{l}\text { Rapid/ultra-rapid } \\
\text { insulin } \\
\text { All physicians }{ }^{\mathrm{a}} \\
(n=549)\end{array}$ & $\begin{array}{l}\text { Intensive insulin } \\
\text { All physicians } \\
(n=549)\end{array}$ \\
\hline \multicolumn{5}{|l|}{ (a) All applicable } \\
\hline DPP-4 inhibitors & $484(88.2)$ & $444(80.9)$ & $424(77.2)$ & $414(75.4)$ \\
\hline Metformin & $419(76.3)$ & $392(71.4)$ & $372(67.8)$ & $358(65.2)$ \\
\hline SGLT-2 Inhibitors & $257(46.8)$ & $214(39.0)$ & $216(39.3)$ & $224(40.8)$ \\
\hline Alpha-GI & $198(36.1)$ & $164(29.9)$ & $137(25.0)$ & $135(24.6)$ \\
\hline SU & $160(29.1)$ & $116(21.1)$ & $116(21.1)$ & $80(14.6)$ \\
\hline GLP-1 RA & $149(27.1)$ & $94(17.1)$ & $98(17.9)$ & $108(19.7)$ \\
\hline Glinides & $124(22.6)$ & $69(12.6)$ & $36(6.6)$ & $26(4.7)$ \\
\hline TZD & $78(14.2)$ & $76(13.8)$ & $61(11.1)$ & $60(10.9)$ \\
\hline $\begin{array}{l}\text { None of them (insulin dose } \\
\text { adjustment only) }\end{array}$ & $10(1.8)$ & $32(5.8)$ & $39(7.1)$ & $55(10.0)$ \\
\hline $\begin{array}{l}\text { Average number of drugs as } \\
\text { combination therapy with } \\
\text { insulin }\end{array}$ & $3.4 \pm 1.5$ & $2.9 \pm 1.5$ & $2.7 \pm 1.4$ & $2.6 \pm 1.5$ \\
\hline Drugs, $n(\%)$ & $\begin{array}{l}\text { ll insulin } \\
\text { physicians } \\
\text { 539) }\end{array}$ & $\begin{array}{l}\text { Pre-mixed insulin } \\
\text { All physicians }{ }^{a} \\
(n=517)\end{array}$ & $\begin{array}{l}\text { Rapid/ultra-rapid insulin } \\
\text { All physicians } s^{a} \\
(n=510)\end{array}$ & $\begin{array}{l}\text { Intensive insulin } \\
\text { All physicians } s^{a} \\
(n=494)\end{array}$ \\
\hline \multicolumn{5}{|l|}{ (b) Frequently used } \\
\hline DPP-4 inhibitors & $(52.3)$ & $259(50.1)$ & $243(47.6)$ & $233(47.2)$ \\
\hline Metformin & $(29.7)$ & $171(33.1)$ & $174(34.1)$ & $159(32.2)$ \\
\hline Alpha-GI & $(4.5)$ & $27(5.2)$ & $27(5.3)$ & $28(5.7)$ \\
\hline SGLT-2 Inhibitors & $(4.3)$ & $24(4.6)$ & $30(5.9)$ & $37(7.5)$ \\
\hline SU & (3.5) & $13(2.5)$ & $11(2.2)$ & $9(1.8)$ \\
\hline Glinides & (2.8) & $9(1.7)$ & $8(1.6)$ & $4(0.8)$ \\
\hline GLP-1 RA & $(2.2)$ & $12(2.3)$ & $13(2.5)$ & $18(3.6)$ \\
\hline TZD & $(0.7)$ & $2(0.4)$ & $4(0.8)$ & $6(1.2)$ \\
\hline
\end{tabular}

All values are mean $\pm \mathrm{SD}$ or $n(\%)$

$D P P-4$ dipeptidyl peptidase-4, GI glucosidase inhibitor, GLP-1 RA glucagon-like peptide-1 receptor agonist, $O A D G$ oral anti-diabetes drugs and glucagon-like peptide-1 receptor agonist, $S G L T-2$ sodium-glucose co-transporter-2, $S U$ sulfonylurea, $T Z D$ thiazolidinedione

${ }^{a}$ Group 1 plus group 2 
Treatment Factors Affecting the Drug Choice for Combination Therapy with Insulin

The glycated hemoglobin (HbA1c) lowering effect, post-prandial glucose (PPG) lowering effect, and low risk of hypoglycemia were the top three treatment factors driving the selection of a DPP-4 inhibitor among the group 1 and group 2 subjects combined across all four types of insulin. Both group 1 and group 2 opted for low cost, improvement in insulin resistance, and high scientific evidence as common treatment factors in addition to the HbA1c-lowering effect for selecting metformin (Table 3a, b). Data presented here were obtained only from those physicians who intended to choose DPP-4 inhibitors or metformin as the first-line choice for add-on to insulin therapy.

\section{Perspectives of Diabetologists and General Physicians}

Treatment factors affecting the choice of either DPP-4 inhibitors or metformin as add-on to insulin therapy are described in Table $3 a$, b. Overall, there was no major difference in factors considered for add-on among all insulin types between group 1 and group 2. The most common treatment factors considered for addition of DPP-4 inhibitor to all insulin types compared with metformin were, for example, the PPGlowering effect, effect on glucagon, and ease of use in patients with renal impairment among group 1 and group 2 subjects. Similarly, for addition of metformin compared with DPP-4 inhibitors, factors such as improvement in insulin resistance, high scientific evidence, and low cost were selected.

\section{Regression Analysis for Drug Features Affecting Selection of DPP-4 Inhibitors or Metformin}

The odds ratios (ORs) between DPP-4 inhibitors and metformin as first-line add-on to insulin therapy considering drug factors are presented in Table $4 \mathrm{a}, \mathrm{b}$. The data represent a pool of major driving factors selected by group 1 and group 2. In general, factors such as the HbA1c/ PPG-lowering effect, effect on glucagon, frequency of administration, and ease of use in patients with renal impairment or liver dysfunction were the main drivers for selecting DPP-4 inhibitors by both group 1 and group 2 (Table $4 a, b$, respectively). PPG-lowering effect was selected mostly by group 1 for basal and pre-mixed insulin combinations. For selection of metformin, cost effectiveness was the major driver. An overall regression analysis on treatment factors affecting choice of drugs (DPP-4 inhibitors and metformin) demonstrated that group 1 tended to consider more treatment factors (14 compared with 10 characteristics considered by group 2) when combining insulin with DPP-4 inhibitors. Low cost for all insulin types was the major drug feature considered by the physicians when considering metformin for insulin combination.

\section{Patient Characteristics Affecting the Treatment Choice for Combination Therapy with Insulin}

Patient characteristics affecting treatment choices (DPP-4 inhibitors or metformin) for combination therapy with insulin are described in Table 5. For DPP-4 inhibitors, both group 1 and group 2 together considered PPG (50.6\%) as the preferred patient feature for combination with all types of insulin, followed by concern about hypoglycemia (50.2\%). For metformin, patient features such as age $(65.6 \%)$, body mass index (BMI) (63.4\%), insulin resistance (51.4\%), renal function (63.1\%), and economic status of patients (33.9\%) were considered by both group 1 and group 2 for combining with all insulin types. Data captured on the choice of patient features for administration of DPP-4 inhibitors or metformin were overall similar between group 1 and group 2 .

\section{DISCUSSION}

The primary objective of this non-interventional study was to identify pertinent factors that affect the selection of OADGs for combination therapy with insulin in patients with 
Table 3 Treatment factors influencing choice of a DPP-4 inhibitor or metformin

\begin{tabular}{|c|c|c|c|c|c|c|c|c|}
\hline \multirow[t]{2}{*}{ Treatment factors } & \multicolumn{2}{|l|}{ Basal } & \multicolumn{2}{|l|}{ Pre-mixed } & \multicolumn{2}{|c|}{ Rapid/ultra-rapid } & \multicolumn{2}{|l|}{ Intensive } \\
\hline & $\begin{array}{l}\text { DPP-4i } \\
(n=122) \\
(\%)\end{array}$ & $\begin{array}{l}\text { Met } \\
(n=90) \\
(\%)\end{array}$ & $\begin{array}{l}\text { DPP-4i } \\
(n=109) \\
(\%)\end{array}$ & $\begin{array}{l}\text { Met } \\
(n=98) \\
(\%)\end{array}$ & $\begin{array}{l}\text { DPP-4i } \\
(n=102) \\
(\%)\end{array}$ & $\begin{array}{l}\text { Met } \\
(n=101) \\
(\%)\end{array}$ & $\begin{array}{l}\text { DPP-4i } \\
(n=102) \\
(\%)\end{array}$ & $\begin{array}{l}\text { Met } \\
(n=93) \\
(\%)\end{array}$ \\
\hline \multicolumn{9}{|l|}{ (a) Group 1} \\
\hline HbAlc-lowering effect & 91.0 & 91.1 & 89.0 & 86.7 & 88.2 & 91.1 & 90.2 & 87.1 \\
\hline PPG-lowering effect & 87.7 & 62.2 & 86.2 & 66.3 & 81.4 & 62.4 & 83.3 & 64.5 \\
\hline Low risk of hypoglycemia & 83.6 & 70.0 & 72.5 & 68.4 & 72.5 & 72.3 & 75.5 & 69.9 \\
\hline No body weight gain & 72.1 & 78.9 & 67.0 & 78.6 & 65.7 & 79.2 & 72.5 & 82.8 \\
\hline FPG-lowering effect & 70.5 & 76.7 & 69.7 & 77.6 & 70.6 & 82.2 & 69.6 & 81.7 \\
\hline Beta cell function protection & 68.0 & 58.9 & 58.7 & 59.2 & 62.7 & 52.5 & 60.8 & 54.8 \\
\hline Effect on glucagon & 64.8 & 38.9 & 62.4 & 38.8 & 59.8 & 38.6 & 62.7 & 35.5 \\
\hline $\begin{array}{l}\text { Easy to use for patients with } \\
\text { renal impairment }\end{array}$ & 56.6 & 15.6 & 57.8 & 13.3 & 58.8 & 10.9 & 55.9 & 8.6 \\
\hline Frequency of administration & 54.1 & 24.4 & 47.7 & 24.5 & 49.0 & 21.8 & 50.0 & 23.7 \\
\hline Effect on insulin & 50.0 & 51.1 & 46.8 & 43.9 & 48.0 & 44.6 & 48.0 & 44.1 \\
\hline CV benefit & 47.5 & 63.3 & 44.0 & 51.0 & 42.2 & 48.5 & 50.0 & 57.0 \\
\hline Low risk of GI side effects & 45.1 & 20.0 & 44.0 & 18.4 & 43.1 & 15.8 & 44.1 & 17.2 \\
\hline $\begin{array}{l}\text { Easy to use for patients with } \\
\text { liver dysfunction }\end{array}$ & 42.6 & 15.6 & 38.5 & 16.3 & 40.2 & 14.9 & 48.0 & 15.1 \\
\hline $\begin{array}{l}\text { Insulin resistance } \\
\text { improvement }\end{array}$ & 41.8 & 87.8 & 45.0 & 87.8 & 53.9 & 84.2 & 48.0 & 89.2 \\
\hline High scientific evidence & 41.8 & 81.1 & 35.8 & 77.6 & 43.1 & 75.2 & 43.1 & 71.0 \\
\hline Low cost & 17.2 & 87.8 & 17.4 & 84.7 & 20.6 & 86.1 & 21.6 & 90.3 \\
\hline \multirow[t]{2}{*}{ Treatment factors } & \multicolumn{2}{|l|}{ Basal } & \multicolumn{2}{|l|}{ Pre-mixed } & \multicolumn{2}{|c|}{ Rapid/ultra-rapid } & \multicolumn{2}{|l|}{ Intensive } \\
\hline & $\begin{array}{l}\overline{D P P}-4 \mathrm{i} \\
(n=160)(\%)\end{array}$ & $\begin{array}{l}\text { Met } \\
(n=70) \%\end{array}$ & $\begin{array}{l}\text { DPP-4i } \\
(n=150) \%\end{array}$ & $\begin{array}{l}\text { Met } \\
(n=73) \%\end{array}$ & $\begin{array}{l}\overline{D P P}-4 \mathrm{i} \\
(n=141) \%\end{array}$ & $\begin{array}{l}\text { Met } \\
(n=73) \%\end{array}$ & $\begin{array}{l}\overline{\text { DPP-4i }} \\
(n=131) \%\end{array}$ & $\begin{array}{l}\text { Met } \\
(n=66) \%\end{array}$ \\
\hline \multicolumn{9}{|l|}{ (b) Group 2} \\
\hline HbAlc-lowering effect & 91.3 & 85.7 & 89.3 & 84.9 & 90.1 & 84.9 & 88.5 & 86.4 \\
\hline PPG-lowering effect & 85.6 & 67.1 & 83.3 & 72.6 & 85.1 & 71.2 & 84.7 & 74.2 \\
\hline Low risk of hypoglycemia & 71.3 & 74.3 & 73.3 & 71.2 & 76.6 & 69.9 & 71.0 & 68.2 \\
\hline No body weight gain & 56.9 & 74.3 & 53.3 & 67.1 & 54.6 & 76.7 & 57.3 & 74.2 \\
\hline FPG-lowering effect & 70.6 & 72.9 & 74.7 & 74.0 & 72.3 & 71.2 & 71.8 & 72.7 \\
\hline Beta cell function protection & 65.6 & 60.0 & 61.3 & 50.7 & 58.9 & 56.2 & 61.1 & 57.6 \\
\hline Effect on glucagon & 51.9 & 28.6 & 55.3 & 23.3 & 51.1 & 23.3 & 55.7 & 31.8 \\
\hline $\begin{array}{l}\text { Easy to use for patients } \\
\text { with renal impairment }\end{array}$ & 50.0 & 15.7 & 53.3 & 9.6 & 52.5 & 12.3 & 54.2 & 10.6 \\
\hline Frequency of administration & 54.4 & 22.9 & 55.3 & 15.1 & 50.4 & 12.3 & 49.6 & 12.1 \\
\hline Effect on insulin & 40.6 & 37.1 & 44.0 & 28.8 & 40.4 & 32.9 & 47.3 & 39.4 \\
\hline CV benefit & 48.1 & 57.1 & 47.3 & 50.7 & 51.1 & 45.2 & 48.9 & 48.5 \\
\hline Low risk of GI side effects & 52.5 & 21.4 & 50.0 & 15.1 & 51.1 & 15.1 & 46.6 & 19.7 \\
\hline $\begin{array}{l}\text { Easy to use for patients } \\
\text { with liver dysfunction }\end{array}$ & 45.0 & 18.6 & 44.7 & 15.1 & 44.7 & 16.4 & 41.2 & 16.7 \\
\hline Insulin resistance improvement & 52.5 & 85.7 & 52.7 & 79.5 & 53.2 & 82.2 & 54.2 & 84.8 \\
\hline High scientific evidence & 43.1 & 74.3 & 38.7 & 67.1 & 37.6 & 63.0 & 37.4 & 68.2 \\
\hline Low cost & 16.3 & 84.3 & 17.3 & 86.3 & 18.4 & 83.6 & 19.1 & 84.8 \\
\hline
\end{tabular}

Treatment factors favoring insulin combination therapy are highlighted for DPP-4 inhibitors (italics) and metformin (bold)

$C V$ cardiovascular, DPP-4i dipeptidyl peptidase-4 inhibitor, FPG fasting plasma glucose, GI gastrointestinal, HbAlc glycated hemoglobin, Met metformin, $P P G$ post-prandial glucose 
T2DM to understand the drug features and physicians (diabetologists and general physicians) perspective behind selecting the treatment regimen in a real-world setting in Japan. The findings from the survey show that DPP-4 inhibitors followed by metformin were the primary preferred choice of add-on treatment to insulin by physicians in Japan.

Response to the survey questionnaire revealed that for both group 1 and group 2, DPP-4 inhibitors have an edge over metformin due to factors such as the PPG-lowering effect, effect on glucagon, and ease of use in patients with renal impairment. The PPG-lowering effect was selected mostly by group 1 compared with group 2, possibly because of the known effectiveness of DPP-4 inhibitors in lowering PPG. Metformin was rated higher for improvement in insulin resistance, scientific evidence, and low cost by group 2. Furthermore, regression analysis demonstrated that group 1 tended to consider more factors to combine DPP-4 inhibitors or metformin with insulin compared with group 2. Except for this observation, there was no major difference between diabetologists and general physicians concerning the OADG choice and background thoughts, which implies that general physicians can be responsible for selecting OADG to combine with insulin.

SGLT-2 inhibitor, glinides, and alpha-GI were frequently combined with insulin when physicians selected all applicable OADGs. This observation could come from the possibility that more than two OADGs are combined with insulin in the real-world clinical setting. The expectations for reducing the insulin dosage or injection frequency with DPP-4 inhibitors and metformin were different between group 1 and 2 ; the latter are assumed to be unaware of different insulin types apart from basal. This could lead to potential variations between group 1 and group 2 in expecting a reduced insulin dosage or injection frequency with metformin.

The reason for DPP-4 inhibitors being prescribed the most frequently could be the low risk of hypoglycemia along with weight neutral effects, which are the most common adverse effects with insulin treatment. Additionally, this could be because of the better glucose- lowering efficacy with DPP-4 inhibitors in studies involving $>50 \%$ Asian populations as demonstrated in a recent meta-analysis [12]. Furthermore, under hypoglycemic conditions, DPP-4 inhibitors are known to induce glucosedependent insulinotropic polypeptide (GIP) mediated augmentation of glucagon secretion, which could be a plausible defense mechanism against hypoglycemia, whereas under high glucose levels, DPP-4 inhibitors suppress glucagon secretion. Through these effects on glucagon dynamics, the potential usefulness of DPP-4 inhibitors as add-on therapy to insulin is supported in several studies $[13,14]$. The increased rate of prescribing DPP-4 inhibitors recently in Japan $[15,16]$ might also be one of the reasons behind the increased frequency of DPP-4 inhibitor use seen in the present study.

Patients' age, renal function, BMI, insulin resistance, and economic status were the main drivers to prescribe metformin against DPP-4. PPG and concern about hypoglycemia drove the decision of prescribing DPP-4 inhibitors. BMI was chosen as one of the important patient features for using metformin although it is effective in non-obese patients as well [17].

Metformin was considered by both group 1 and group 2 because of its cost-effectiveness and its effect on improving insulin resistance in patients with T2DM. The finding that metformin is one of the two most prevalent initial prescriptions is in line with the treatment algorithm recommended by the ADA and the EASD [5] and mostly followed in Japan. In the present study, SGLT-2 inhibitors seem to be a preferred choice of treatment after metformin as a combination therapy with insulin. The reason for more prescriptions for SGLT-2 inhibitors could be the low risk of hypoglycemia, weight benefits, and their recently demonstrated CV safety profile [18-20].

\section{STRENGTHS AND LIMITATIONS}

A major limitation of this study is its non-interventional nature, in addition to information and selection bias, and limitations of feasibility. Lack of patient data impeded further understanding the consideration of T2DM duration, 


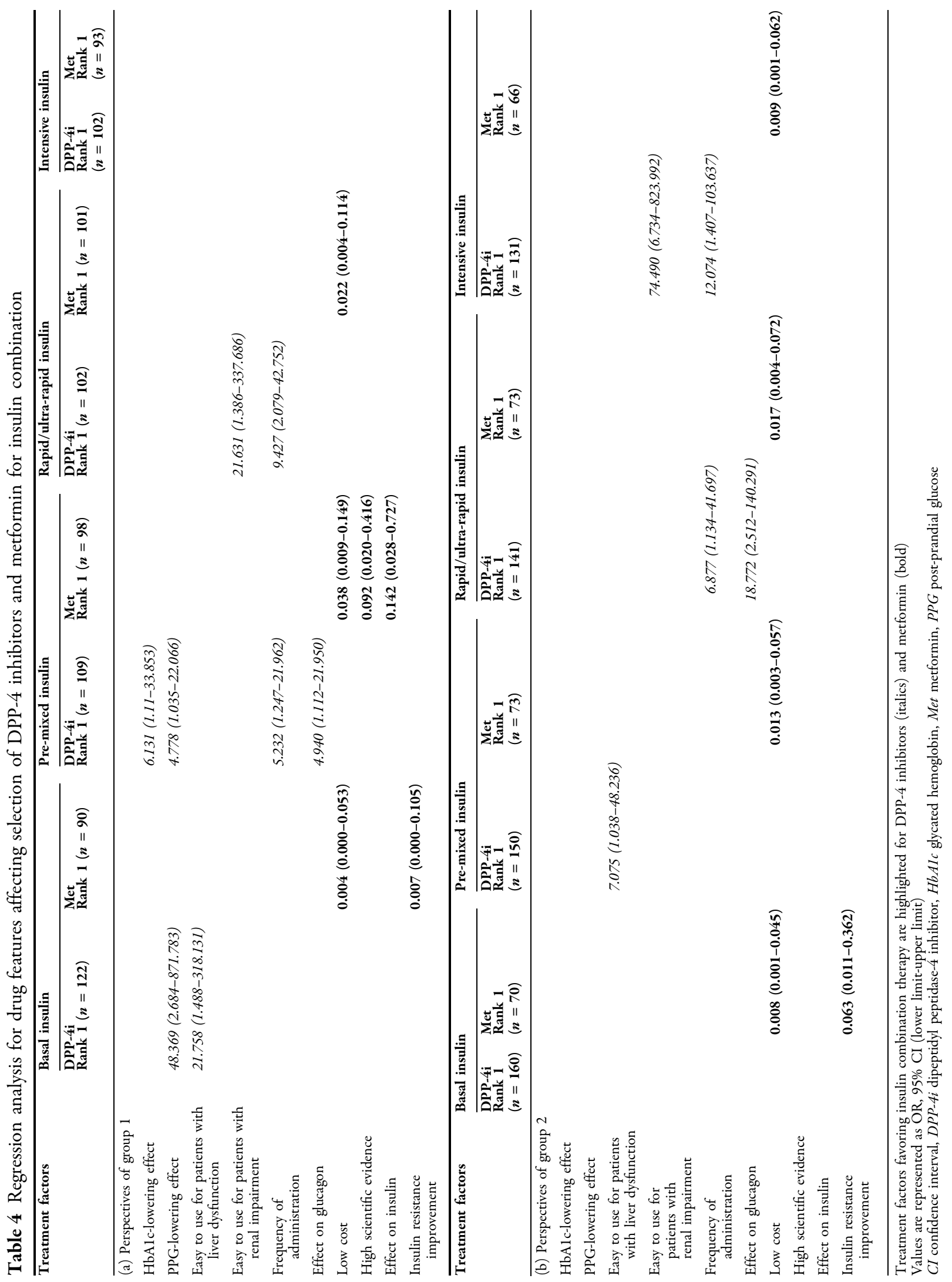




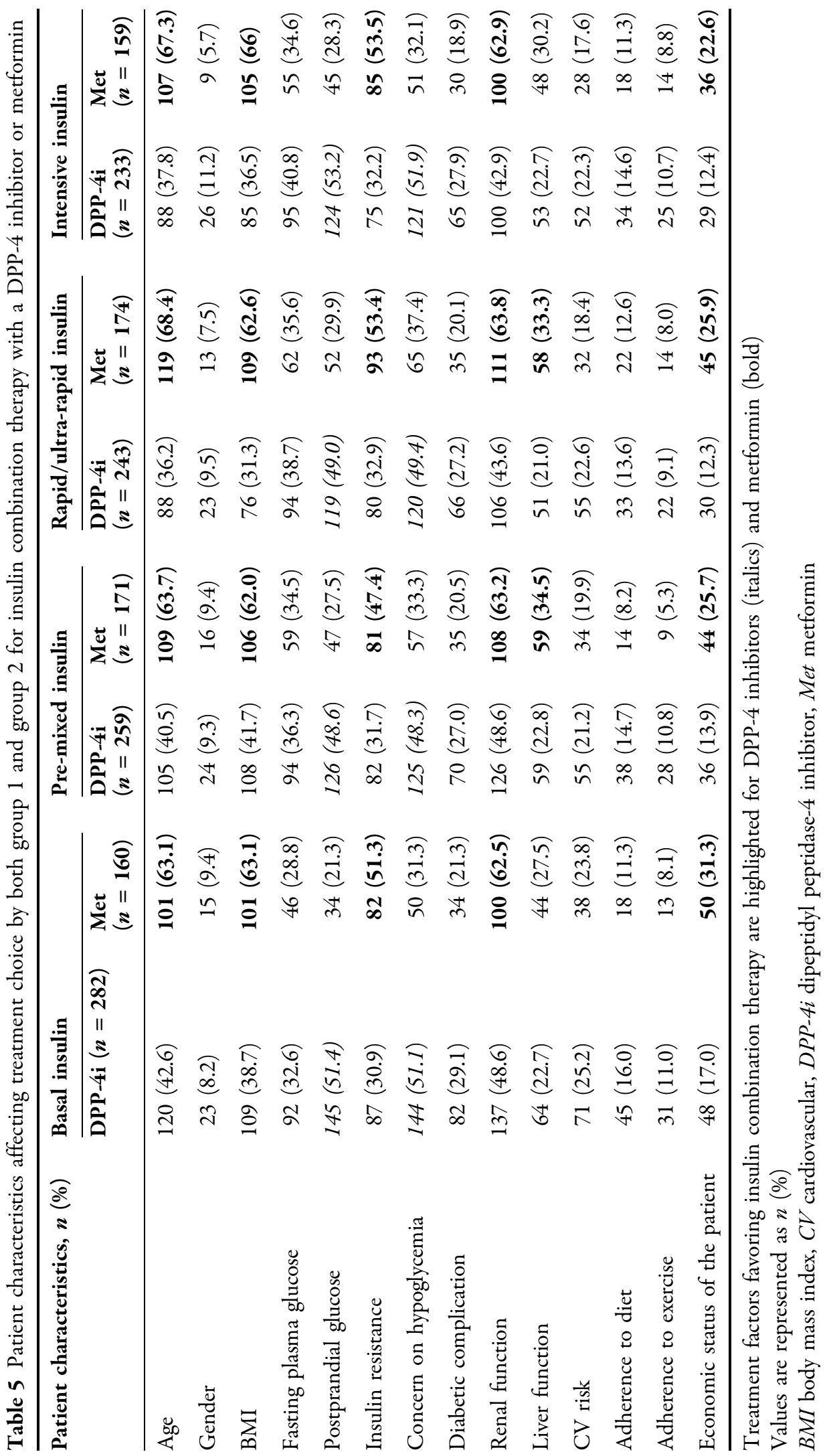


HbA1c levels at baseline, BMI, and comorbidities by physicians while prescribing an OADG as an add-on therapy to insulin. In addition, we focused only on DPP-4 inhibitors and metformin to examine factors affecting OADG choice for combination therapy with insulin since these drugs were predominant. Further studies are needed to examine other drugs such as SGLT-2 inhibitors or sulfonylurea to understand factors affecting the choice of these drugs for sophisticated diabetes treatment. Nevertheless, the present findings from the survey add valuable data to the evidence base and may provide discussion topics to consider the difference in T2DM treatment with insulin between Japanese patients and those from other counties.

\section{CONCLUSION}

Despite variations in perspectives with respect to the choice of treatment factors and patient characteristics among diabetologists and general physicians, DPP-4 inhibitors, followed by metformin, were the most frequently prescribed OADs as add-on therapy to all insulin types across Japan. Further studies are warranted to test the potential of other OADGs and better understand the treatment factors and characteristics of patients with T2DM.

\section{ACKNOWLEDGEMENTS}

The authors sincerely thank the physicians who participated in the survey. The authors also thank Saraf Megha, Novartis Healthcare Pvt. Ltd, Hyderabad, India, for her support in conducting the survey and data analysis for the manuscript.

Funding. Sponsorship and article processing charges for this study were funded by Novartis Pharma KK.

Medical Writing and Editorial Assistance. Medical writing and editorial assistance, in accordance with Good Publication Practice guidelines (http://www.ismpp.org/gpp3), as well as the collation and incorporation of comments from all authors for this study were provided by Rangan Gupta and G. Lakshmi Deepa of Novartis Healthcare Private Ltd, Hyderabad, India, and were funded by Novartis Pharma KK.

Authorship. All named authors meet the International Committee of Medical Journal Editors (ICMJE) criteria for authorship for this manuscript and contributed to the conception, design, and interpretation of the analysis. All the authors had full access to the data and assume complete responsibility for the integrity of the data and approved the final manuscript for submission.

Disclosures. Kota Imai is an employee of Novartis Pharma K.K. Hiroki Murayama is an employee of Novartis Pharma K.K. Takahisa Hirose has served as an advisory board member for Novartis and has received consultancy fees, lecture fees, or research funding from Novartis Pharma K.K., Sanofi Eli Lilly Co., Novo Nordisk Pharma Ltd., Takeda Pharmaceutical Co. Ltd., Daiichisankyo Co. Ltd., MitsubishiTanabe Pharma Corp., DainipponSumitomo, AstraZeneca, Bayer, TaishoToyama Pharmaceutical Co. Ltd., Asteras Pharma, Inc., Ono Pharmaceutical Co. Ltd., MSD, Kissei Pharmaceutical Co. Ltd., and Boehringer Ingelheim. No other potential conflicts of interest relevant to this article were reported.

Compliance with Ethics Guidelines. The study was conducted in accordance with the Ethical Guidelines for Medical and Health Research Involving Human Subjects (the Ministry of Education, Culture, Sports, Science and Technology, and the Ministry of Health, Labor and Welfare, Japan) and with the 1964 Helsinki declaration and its later amendments or comparable ethical standards. The study protocol was reviewed and approved by a central ethics committee (EC) in Osaka.

Data Availability. The data sets generated during and/or analyzed during the current study are available from the corresponding author upon reasonable request. All authors had 
full access to all of the data in this study and take complete responsibility for the integrity of the data and accuracy of the data analysis.

Open Access. This article is distributed under the terms of the Creative Commons Attribution-NonCommercial 4.0 International License (http://creativecommons.org/licenses/ by-nc/4.0/), which permits any noncommercial use, distribution, and reproduction in any medium, provided you give appropriate credit to the original author(s) and the source, provide a link to the Creative Commons license, and indicate if changes were made.

\section{REFERENCES}

1. International Diabetes Federation. IDF diabetes atlas. 8th ed. Brussels: International Diabetes Federation; 2017.

2. Evidence-Based Practice Guideline for the Treatment for Diabetes in Japan. 2013. http://www.jds. or.jp/modules/en/index.php?content_id=44. Accessed 10 Oct 2017.

3. Morimoto A, Tatsumi Y, Deura K, et al. Impact of impaired insulin secretion and insulin resistance on the incidence of type 2 diabetes mellitus in a Japanese population: the Saku study. Diabetologia. 2013;56:1671-9.

4. Fukushima M, Suzuki H, Seino Y. Insulin secretion capacity in the development from normal glucose tolerance to type 2 diabetes. Diabetes Res Clin Pract. 2004;66:S37-43.

5. Inzucchi SE, Bergenstal RM, Buse JB, et al. Management of hyperglycaemia in type 2 diabetes, 2015: a patient-centred approach. Update to a position statement of the American Diabetes Association and the European Association for the Study of Diabetes. Diabetologia. 2015;58:429-42.

6. Currie CJ, Poole CD, Evans M, Peters JR, Morgan CL. Mortality and other important diabetes-related outcomes with insulin vs other antihyperglycemic therapies in type 2 diabetes. J Clin Endocrinol Metab. 2013;98:668-77.

7. Sato S, Saisho Y, Kou K, et al. Efficacy and safety of sitagliptin added to insulin in Japanese patients with type 2 diabetes: the EDIT randomized trial. PLoS ONE. 2015;10:e0121988.
8. Fujihara K, Hanyu O, Heianza Y, et al. Comparison of clinical characteristics in patients with type 2 diabetes among whom different antihyperglycemic agents were prescribed as monotherapy or combination therapy by diabetes specialists. J Diabetes Investig. 2016;7:260-9.

9. Home PD, Dain MP, Freemantle N, et al. Four-year evolution of insulin regimens, glycaemic control, hypoglycaemia and body weight after starting insulin therapy in type 2 diabetes across three continents. Diabetes Res Clin Pract. 2015;108:350-9.

10. American Diabetes Association. 2018. Standards of medical care in diabetes guideline. http://care. diabetesjournals.org/content/diacare/suppl/2017/ 12/08/41.Supplement_1.DC1/DC_41_S1_Combined. pdf. Accessed 02 Feb 2018.

11. Lavernia F, Adkins SE, Shubrook JH. Use of oral combination therapy for type 2 diabetes in primary care: meeting individualized patient goals. Postgrad Med. 2015;127:808-17.

12. Kim YG, Hahn S, Oh TJ, Kwak SH, Park KS, Cho YM. Differences in the glucose-lowering efficacy of dipeptidyl peptidase- 4 inhibitors between Asians and non-Asians: a systematic review and metaanalysis. Diabetologia. 2013;56:696-708.

13. Farngren J, Persson M, Schweizer A, Foley JE, Ahrén B. Glucagon dynamics during hypoglycaemia and food-re-challenge following treatment with vildagliptin in insulin-treated patients with type 2 diabetes. Diabetes Obes Metab. 2014;16:812-8.

14. Malmgren S, Ahrén B. DPP-4 inhibition contributes to the prevention of hypoglycaemia through a GIPglucagon counter regulatory axis in mice. Diabetologia. 2015;58:1091-9.

15. Oishi M, Yamazaki K, Okuguchi F, et al. Changes in oral antidiabetic prescriptions and improved glycemic control during the years 2002-2011 in Japan (JDDM32). J Diabetes Investig. 2014;5:581-7.

16. Kohro $T$, Yamazaki $T$, Sato $H$, et al. Trends in antidiabetic prescription patterns in Japan from 2005 to 2011. Int Heart J. 2013;54:93-7.

17. Ito $\mathrm{H}$, Ishida $\mathrm{H}$, Takeuchi $\mathrm{Y}$, Antoku $\mathrm{S}$, Abe $\mathrm{M}$, Mifune $M$, Togane M. Long-term effect of metformin on blood glucose control in non-obese patients with type 2 diabetes mellitus. Nutr Metab (Lond). 2010;12(7):83. https://doi.org/10.1186/ 1743-7075-7-83.

18. Yang Y, Chen S, Pan H, et al. Safety and efficiency of SGLT2 inhibitor combining with insulin in subjects with diabetes: systematic review and meta-analysis 
of randomized controlled trials. Medicine (Baltimore). 2017;96:e6944.

19. Neal B, Perkovic V, Mahaffey KW, et al. Canagliflozin and cardiovascular and renal events in type 2 diabetes. N Engl J Med. 2017;377:644-57.
20. Zinman B, Wanner C, Lachin JM, et al. Empagliflozin, cardiovascular outcomes, and mortality in type 2 diabetes. N Engl J Med. 2015;373:2117-28. 